\title{
Resource allocation during spoken discourse processing: Effects of age and passage difficulty as revealed by self-paced listening
}

\author{
DEBRA TITONE, KRISTEN J. PRENTICE, and ARTHUR WINGFIELD \\ Brandeis University, Waltham, Massachusetts
}

\begin{abstract}
The allocation of processing resources during spoken discourse comprehension was studied in a manner analogous to self-paced reading using the auditory moving window technique (Ferreira, Henderson, Anes, Weeks, \& McFarlane, 1996). Young and older participants listened to spoken passages in a self-paced segment-by-segment fashion. In Experiment 1, we examined the influence of speech rate and passage complexity on discourse encoding and recall performance. In Experiment 2, we examined the influence of speech rate and presentation mode (self-paced vs. full-passage presentation) on recall performance. Results suggest that diminished memory performance in the older adult group relative to the young adult group is attributable to age-related differences in how resources were allocated during the initial encoding of the spoken discourse.
\end{abstract}

Listening to, and comprehending, natural speech requires effective organization of the input as it is being heard both in terms of linguistic constituents and higher order elements at the discourse level. Although discourse processing theories differ in detail, limitations in memory or processing resources are generally assumed to limit the effectiveness of language processing, whether at interpretive or postinterpretive stages (Caplan \& Waters, 1999; Carpenter, Miyaki, \& Just, 1994; Daneman \& Merikle, 1996; Kintsch, 1994; van Dijk \& Kintsch, 1983; Waters \& Caplan, 1996). In using the term resources, we refer to a pool of mental energy that is presumed to underlie the successful execution of cognitive tasks. As such, tasks will be less effectively conducted when their resource demands are high or when the processing system has reduced resources (Craik \& Byrd, 1982; Kahneman, 1973; Salthouse, 1991; Stine, 1995). One way memory or resource constraints on language processing have been studied is through experimental comparisons between healthy young and older adults because of the common finding that older adults are at a disadvantage relative to young adults on tests of working memory or attentional resource capacity (Craik \& Byrd, 1982; Salthouse \& Babcock, 1991; Wingfield, Stine, Lahar, \& Aberdeen, 1988).

Although some theorists have focused on age-related reductions in resource capacity, others have focused on

We acknowledge support from NIH Grant R3? AG04517 from the National Institute on Aging and support from the W.M. Keck Foundation. D.T. also acknowledges support from NIH Training Grant T32 AG00204 to Brandeis University. We thank Lisa Connor, Fergus Craik. Lisa Miller, Elizabeth Stine-Morrow, and Deborah Little for comments on earlier versions of this manuscript. Correspondence should be addressed to A. Wingfield, Volen National Center for Complex Systems (MS 013), Brandeis University, Waltham, MA 02454-9110 (e-mail: wingfield@brandeis.edu). possible age differences in the effective allocation of these resources. An example of this latter view is the selfinitiation hypothesis of Craik and Jennings (1992), which suggests that older adults are less able to successfully direct attentional resources to where they are needed, especially when performing a task that is particularly difficult. Applied to tasks such as discourse processing, this view would imply that "automatic" aspects of discourse processing should be performed similarly by young and older adults, whereas less automatic aspects of the discourse processing task, such as elaborative inferencing and the integration of information, would not be as consistently well performed by older adults (Stine, Loveless, \& Soederberg, 1996). Consistent with this hypothesis, a number of reading time studies have shown that older adults, unlike young adults, are less likely to slow their reading at sentence boundaries, an important area for integration during comprehension (Stine, 1990; Stine, Cheung, \& Henderson, 1995). That is, older adults are less likely than young adults to allocate attentional resources where text demands are greatest. Given that linguistic knowledge is well preserved in normal aging (Light, 1990), age differences in patterns of resource allocation in discourse processing might be a major contributor to the significant age-related declines in recall of written and spoken discourse (Hartley, 1993; Wingfield \& Stine, 1992).

One way to better understand the nature of older adults' discourse processing is to examine the extent to which age-related encoding failures relate to impaired memory performance for discourse. Reading time studies using the moving window or related techniques (Aaronson \& Ferres, 1984; Aaronson \& Scarborough, 1976; Just, Carpenter, \& Woolley, 1982; Magliano, Graesser, Eymard, Haberlandt, \& Gholson, 1993) have shown that older adults spend less time than young adults reading important regions of text, although they are very similar to young 
adults in many other ways (Hartley, 1986, 1993; Hartley, Stojack, Mushaney, Annon, \& Lee, 1994). In one study that exemplifies this approach, Stine et al. (1996) visually presented expository passages to a group of young and older adults for immediate recall. Each passage was presented one sector at a time and a participant-initiated keypress triggered presentation of each new sector. This procedure allowed for reading time to be measured for each sector of text, thus providing a measure of how young and older adults allocated attentional resources to different regions of the texts during encoding.

Stine et al. (1996) found that both age groups showed a sensitivity in their reading times to different levels of the texts (e.g., word, sentence, and discourse levels). Older adults' reading times were shorter than those of the young, however, specifically at clause boundaries. Stine et al. suggested that this difference in patterns of reading time probably resulted in a less stable memory trace of text information for older adults because clause boundaries are important computational points for integrating information. They also argued that the similarities in reading behavior between the groups could be seen as reflecting a lack of compensation by the older adults for age-related memory or resource constraints. They concluded that successful performance requires that older adults modify their behavior to overcome these age-related limitations.

\section{The Unique Problem of Spoken Discourse Comprehension}

Although resource allocation during the reading of discourse has received considerable attention, the results from this work may not be entirely generalizable to the domain of listening. Comprehenders of spoken discourse are faced with an inherently transient and noisy signal, and their control over the flow of information during spoken conversation is bound to be much coarser than a reader's control of how the eye moves across written text. Even in word-by-word or sector-by-sector reading time experiments in which comprehenders cannot backtrack to read previous portions of a text, it is still the case that readers can take as long as they need to fully encode a particular word or segment before initiating the next segment. Listeners, by contrast, must hold the transient acoustic forms in memory until they are processed. Such differences might thus result in a more memory-demanding task environment for listeners than for readers.

One difficulty researchers have faced in addressing the question of spoken discourse processing is finding an adequate experimental method with which to study immediate encoding of spoken discourse (i.e., "listening" behavior). Wingfield and Butterworth (1984) employed a technique called spontaneous segmentation to study the encoding of spoken discourse. In this paradigm, listeners control the flow of spoken input by interrupting recorded speech for intermediate recall at points of their choosing. This technique shows that listeners will reliably interrupt the prose input at commonly defined syn- tactic boundaries (Wingfield \& Butterworth, 1984). Additionally, Wingfield and Lindfield (1995) showed that for both normal and rapid speech, young and older adults typically interrupt speech for recall at similar points (clause and sentence boundaries), although older adults recall less of their selected segments than do young adults, especially with faster speech rates. These results suggest that the older adults' maintenance of an encoding strategy that was appropriate for young adults does not serve them well for ultimately recalling information from spoken passages.

Although this technique suggests strong similarities between young and older adults in spoken language encoding, there might be differences in encoding patterns that the spontaneous segmentation paradigm does not capture. Young and older participants, for example, might be differentially sensitive to text characteristics other than syntactic boundary structure. Such text characteristics might range from word-level variables, such as word frequency, to the overall conceptual structure at the discourse level.

A useful technique for answering this question is the so-called auditory moving window (AMW) technique developed by Ferreira and colleagues (Ferreira \& Anes, 1994; Ferreira, Anes, \& Horine, 1996; Ferreira, Henderson, Anes, Weeks, \& McFarlane, 1996). Analogous to selfpaced reading, the method has been successfully used to study how listeners encode spoken text. In this technique, participants are given direct control of the temporal flow of speech as it is being heard. Participants listen to spoken language that is presegmented at units (e.g., word or multiword length) chosen by the experimenter. The presentation of each segment is initiated by a listener-controlled keypress. Of interest is the duration of listeners' pauses between the end of one segment and their initiation of the subsequent segment. Ferreira and colleagues have used this technique to examine listening behavior for word-by-word presentations of sentences and have found that, similar to word-by-word reading techniques, AMW is sensitive to lexical frequency effects and syntactic garden path effects (Ferreira, Henderson, et al., 1996).

A potential concern with the AMW technique is that it presents spoken language in a way that listeners do not normally encounter (i.e., in word or multiword segments). Using this technique, however, Ferreira, Henderson, et al. (1996) have shown positive effects for the influence of prosodic information. This suggests that, although pause information might be reduced, presenting spoken language in segments does not appreciably disrupt the perception of intonation, vowel lengthenings, and stress patterns that accompany natural speech (Ferreira, Henderson, et al., 1996).

\section{The Present Study}

Given the work on adult age differences in discourse processing during reading, we were specifically interested in testing the extent to which resource limitations in 
older adults, whether resulting from capacity limits or deficits in the ability to self-initiate resources, impact the encoding of, and consequently memory performance for, spoken discourse. According to Craik and Jennings's (1992) self-initiation hypothesis, older adults should less effectively encode spoken discourse when it is highly resource demanding. Translated to the AMW paradigm, older adults should spend less time than young adults at resource demanding regions of the passages, especially when difficulty of the overall discourse comprehension task is increased.

In pursuit of this goal, we utilized a discourse processing version of the AMW technique. Young and older adults listened to spoken discourse passages in a segmentby-segment fashion (i.e., each segment contained multiple words). Spoken passages differing in contextual predictability (i.e., high or low) were presented to young and older adults at normal and accelerated speech rates. By manipulating the contextual predictability and speech rate of the passages, we wished to target unique sources of difficulty in the discourse listening task. In this experiment, we follow the general argument of Stine et al. (1996) in their interpretation of reading times. Specifically, participants' pause durations at the end of each spoken segment are taken as an index of the relative amount of resources allocated by the participant to analyzing and integrating information provided by the previous segment. Longer pause durations are taken to reflect participants' allocation of more resources to comprehension at that point in the discourse passage; shorter pause durations indicate that participants devoted fewer resources to comprehension at that point in the discourse.

A second interest was to explore potential age differences in the efficacy of particular encoding patterns in producing good recall. Specifically, if older adults are less effective than young adults in allocating resources during the encoding of spoken discourse, we would expect that their ability to recall the discourse material would not appreciably improve when given the opportunity to listen in a self-directed way. In contrast, we would expect such an improvement in the young. In terms of encoding behavior, we predicted that age-related differences in effective encoding strategy would take the form of older adults spending relatively less time than younger adults pausing at critical regions of the discourse passages. Such critical regions include syntactic boundaries within and between sentences and the beginnings of spoken texts.

\section{EXPERIMENT 1}

\section{Method}

Participants. The young adults were 22 university undergraduates, 13 women and 9 men, with ages ranging from 16 to 20 years ( $M=18.8$ years). The older adults were 22 volunteers from the community, 14 women and 8 men, with ages ranging from 60 to 82 years ( $M=73.3$ years). The young adult group had a mean of 12.5 years of education at time of testing $(S D=1.0)$, and the older adult group had a mean of 15.7 years of education $[S D=2.2 ; t(42)=$
$6.33, p<.05]$. The young adult group had a mean score on the Wechsler Adult Intelligence Scale-Revised (WAIS-R; Wechsler, $1981)$ vocabulary test of $61(S D=6.7)$, and the older adult group had a mean vocabulary score of $71.3[S D=6.5 ; t(42)=5.25, p<$ $.01]$. Thus, any age differences in favor of the young obtained in this experiment would not be due to any superiority in vocabulary or education level on the part of the young participants.

Prior to the experiment, all participants were given a spoken word span test in which they heard progressively longer word lists, consisting of common unrelated nouns, for immediate recall. Participants heard two lists of each length, increasing up to nine words. Word span was taken as the maximum length at which at least one of the two lists was completely reported without respect to order. Unlike other simple span tests such as the forward and backward digit span tests, the word span test has been shown to correlate significantly with more complex memory tests such as Daneman and Carpenter's (1980) working memory span test (Wingfield et al., 1988 ), as well as with age differences in text recall (Stine \& Wingfield, 1990). As would be expected on the basis of previous research (e.g., Wingfield et al., 1988), the young adult group had a higher score $(M=6.1$ words, $S D=.9)$ than did the older adult group $[M=5.1, S D=.9 ; t(42)=3.8, p<.01]$.

All of the participants were healthy and well educated. None were neurologically compromised by stroke or had any sign of dementing illness, and all had hearing acuity appropriate to their age group as revealed by pure-tone audiometric screening.

Stimulus Materials. Stimulus materials consisted of eight 150word passages taken from G. R. Miller and Coleman (1967) that had been calibrated for overall contextual predictability using an interword "cloze" procedure. The probability that comprehenders will think of a particular word deleted from a text is a convenient summary statistic that reflects the combined effects of the syntactic, semantic, and pragmatic constraints that operate on word choice. Prior work using these passages has shown that their predictability scores correlate highly with subjective estimates of passage difficulty and actual passage recall (Acquino, 1969; Riggs, Wingfield, \& Tun, 1993).

Four of the 8 passages, hereafter referred to as low-predictability passages, had a mean predictability rating of .55 , and 4 passages, hereafter referred to as high-predictability passages, had a mean predictability rating of 71 . Each of the passages was recorded by a female speaker of American English in a natural manner at a comfortable mean speaking rate of 167 words per minute (wpm). The recorded passages were then digitized at a sampling rate of $22 \mathrm{kHz}$ and stored for editing and presentation using a computer-based speech editing system.

Selection of where to segment the passages was constrained by two main methodological considerations. First, we wanted to minimize segment length variability across the passages, and second, we wanted to avoid placing segmentation boundaries between words that had no visible boundary when examined using a waveform editor. Consequently, we tried to segment the discourse passages into relatively uniform units where naturally occurring pauses between words were evident. This procedure resulted in segmentations that were introduced at three boundary types: within clause, end-of-clause, and end-of-sentence boundaries. For the lowpredictability passages, within-clause boundaries accounted for $21 \%$ of all segments across passages, end-of-clause boundaries for $41 \%$, and end-of-sentence boundaries for $38 \%$. For the highpredictability passages, within-clause boundaries accounted for $24 \%$ of all segments across passages, end-of-clause boundaries for $42 \%$, and end-of-sentence for $34 \%$. All speech segments were timecompressed to $99 \%$ and $60 \%$ of their original duration, creating stimuli for a normal speech rate condition and an accelerated speech rate condition, respectively. This resulted in an average speech rate of $168 \mathrm{wpm}$ for the normal rate passages and $278 \mathrm{wpm}$ for the ac- 
Table 1

Passage Characteristics

\begin{tabular}{|c|c|c|c|c|c|c|c|c|}
\hline \multirow[b]{3}{*}{ Text Characteristic } & \multicolumn{8}{|c|}{ Passage Type } \\
\hline & \multicolumn{4}{|c|}{ High Predictability } & \multicolumn{4}{|c|}{ Low Predictability } \\
\hline & PI & $\mathrm{P} 2$ & P3 & P4 & P5 & P6 & P7 & P8 \\
\hline Cloze predictability & .78 & .69 & .69 & .67 & .63 & .56 & .56 & .47 \\
\hline No. sentences & 10 & 9 & 8 & 9 & 11 & 10 & 10 & 11 \\
\hline No. segments & 29 & 24 & 25 & 27 & 31 & 28 & 26 & 26 \\
\hline$M$ propositional density per segment* & 1.7 & 2.8 & 2.4 & 2.1 & 2.2 & 2.9 & 2.5 & 2.8 \\
\hline$M$ no. syllables per segment & 6.4 & 7.3 & 7.7 & 6.7 & 7.0 & 6.9 & 8.0 & 7.8 \\
\hline \multicolumn{9}{|l|}{$M$ word frequency per segment } \\
\hline (content words only) $\dagger$ & 906 & 1,061 & 1,139 & 961 & 1,050 & 999 & 1,152 & 1,182 \\
\hline$\%$ within-clause boundaries & 24 & 25 & 20 & 26 & 16 & 25 & 23 & 19 \\
\hline$\%$ end-of-clause boundaries & 41 & 38 & 48 & 41 & 48 & 39 & 38 & 38 \\
\hline$\%$ end-of-sentence boundaries & 34 & 38 & 32 & 33 & 35 & 36 & 38 & 42 \\
\hline
\end{tabular}

*Propositional density is calculated as the ratio between the number of propositions in a sentence and the number of segments in that sentence. ${ }^{+}$Word frequency refers to the relative frequency of the occurrence of a word per 1 million in print (Francis \& Kučera, 1982).

celerated passages. The characteristics of the 8 passages are given in Table 1, and examples of high- and low-predictability passages are given in the Appendix.

Procedure. Participants were tested individually and were told that they would hear a series of short passages of English speech recorded at varying speech rates. The instructions were to listen to each passage and to verbally recall each passage as accurately as possible at its conclusion. Although the participants knew that they would be tested for accuracy of later recall, they were nevertheless encouraged to listen to the passages for comprehension rather than to attempt to study them in a word-for-word fashion.

Passages were presented in a self-paced, segment-by-segment fashion. Participants were instructed to press an appropriately labeled key that initiated presentation of the individual segments of the passage. The first keypress initiated presentation of the first segment of a passage, and each subsequent keypress initiated presentation of each subsequent segment of the passage. The computer automatically measured the time duration between the offset of a speech segment and the onset of the participant's keypress response to initiate the presentation of the next segment (hereafter referred to as pause duration). The experiment was designed so that only keypresses made after the offset of an acoustic segment triggered presentation of subsequent segments and were recorded. Inappropriately premature keypresses had no effect on presentation of the current segment or on that of subsequent segments. It was emphasized that participants should proceed through each passage at a comfortable pace. Participants were told that our interest was in the accuracy of their recall, and they were unaware that keypressing latencies were being recorded.

Each participant heard a total of 8 passages, 4 high-predictability passages and 4 low-predictability passages. Within each predictability condition, 2 passages were presented in the normal speech rate condition, and 2 were presented in the accelerated speech rate condition. Passage presentation order was counterbalanced across participants, and no passage was heard more than once by a participant. Passages and speech rates were also counterbalanced so that by the end of the experiment each passage was presented an equal number of times at the normal and accelerated speech rates.

Stimuli were presented on a Macintosh computer using the PsyScope experimental program (Cohen, MacWhinney, Flatt, \& Provost, 1993). Participants' verbal recall was recorded on tape and later transcribed for scoring according to the gist criterion outlined by Turner and Greene (1978). Materials were presented binaurally over earphones at a comfortable listening level, adjusted individually for each participant. Prior to the main experiment, all participants re- ceived a brief practice session with 2 passages not used in the main experiment to familiarize them with the self-paced listening task and the recall requirement.

\section{Results}

Pause durations. Figure 1 shows mean pause durations in milliseconds for the young and older adults in the first, second, and final thirds of the high-predictability (left upper and lower panels) and low-predictability (right upper and lower panels) passages. In each panel these data are shown separately for pauses occurring at the ends of sentences, the ends of clauses, and within clauses. A 2 (age: young, older) $\times 2$ (passage predictability: low, high) $\times 3$ (boundary type: within clause, end of clause, end of sentence) $\times 3$ (passage position: first third, second third, final third) $\times 2$ (speech rate: normal, accelerated) mixed-design analysis of variance (ANOVA) was conducted on these data. Lines of best fit across passage position are plotted for each of the conditions and text variables. (These data are collapsed across speech rates because rate produced no significant effect on the pattern of pause durations $[F(1,42)<1]$. The results of the ANOVA confirmed the major trends and interactions suggested by Figure 1.

As can be seen in Figure 1, average pause durations collapsed across all segments did not significantly differ for young and older adults $[F(1,42)<1]$. Additionally, for both young and older participants, the heights of the curves in each of the four panels indicate that pause durations increased with the importance of the linguistic boundary, producing a significant main effect of boundary type $\left[F(2,92)=50.08, M S_{\mathrm{e}}=113,635, p<.01\right]$. Figure 1 also shows that pause durations for end-ofsentence boundaries, typically presumed to be important integration regions, show a general decline across passages for young adults, and a general increase across passages for older adults, a pattern confirmed by a significant age $\times$ passage position interaction $[F(2,84)=5.55$, $\left.M S_{\mathrm{e}}=232,372, p<.01\right]$. Finally, young adults spent sig- 


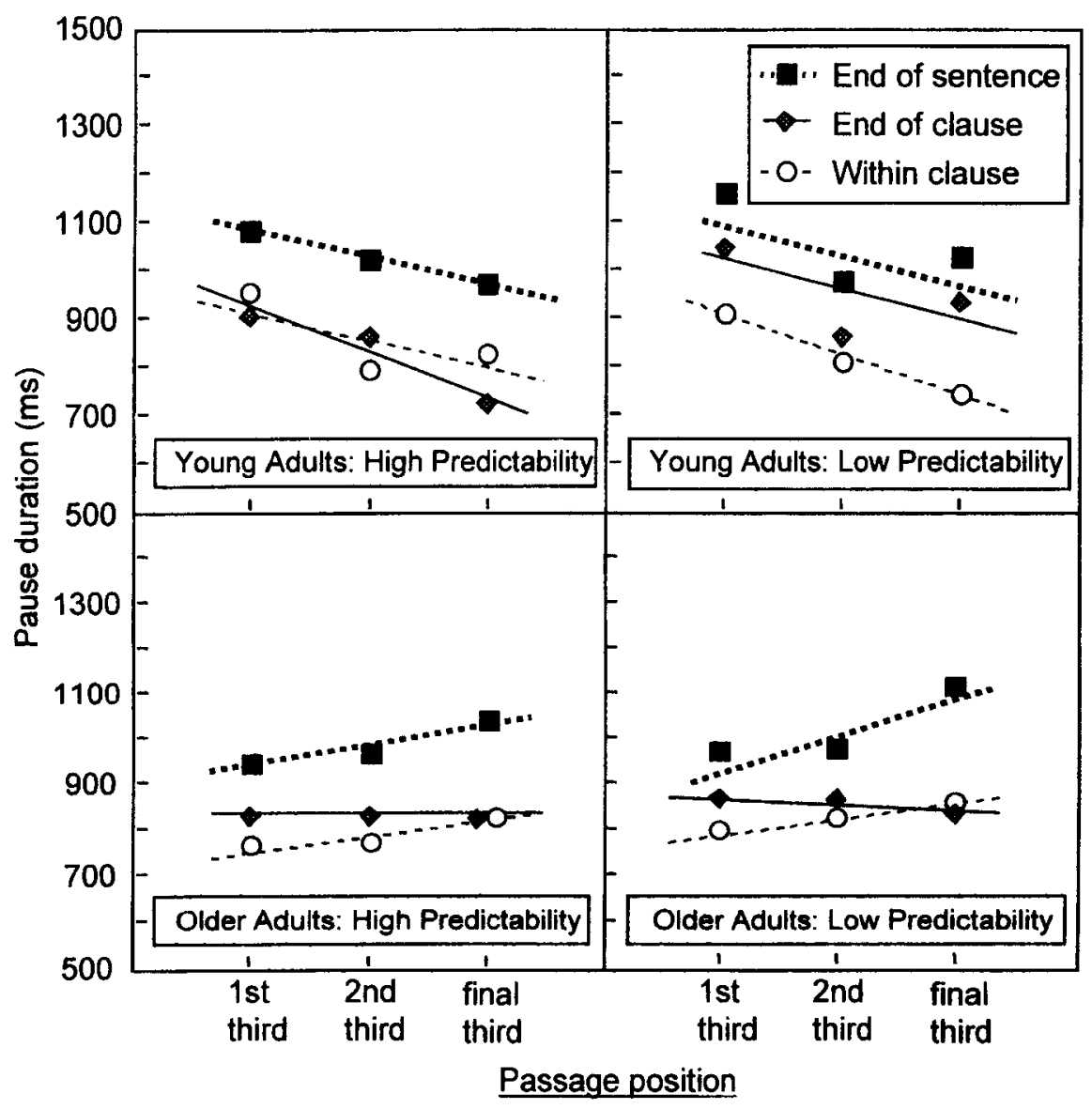

Figure 1. Mean pause duration in milliseconds in Experiment 1 as a function of age, passage predictability, passage position, and boundary type.

nificantly more time at clause boundaries than at withinclause boundaries for low-predictability passages. This was confirmed by a significant age $x$ boundary type $X$ passage predictability interaction $\left[F(2,84)=5.41, M S_{\mathrm{e}}=\right.$ $42,208, p<.01]$. The age interactions with passage position and boundary type suggest that young adults, but not older adults, are able to modify their listening behavior to accommodate decreases in contextual predictability. None of the remaining main effects or interactions were significant.

We also conducted a stepwise regression analysis in order to assess the extent to which pause durations were influenced by particular characteristics of the passages. This analysis showed that listeners were sensitive to characteristics such as the accumulation of segments across a sentence and across a passage, as well as propositional density, average word frequency, and segment length. ${ }^{1}$

To determine whether 1 or 2 passages might have had a disproportionate impact on the results, we also conducted an item analysis on these data. It is important to note, however, that the results of this item analysis should be viewed with caution since they represent only 2 passages per condition. As in the participant analysis, there was a significant main effect of passage position $[F 2(2,12)$ $\left.=6.63, M S_{\mathrm{e}}=84,412, p<.05\right]$, a significant age $\times$ passage position interaction $\left[F 2(2,12)=6.09, M S_{\mathrm{e}}=84,412\right.$, $p<.05]$, and a marginally significant age $\times$ boundary type interaction $\left[F 2(2,12)=3.38, M S_{\mathrm{e}}=128,201, p=\right.$ $.06]$. However, the predictability $\times$ position $\times$ boundary type interaction was significant $\left[F(4,24)=4.40, M S_{\mathrm{e}}=\right.$ $51,867, p<.01]$, as was the age $\times$ predictability $\times$ position $\times$ boundary type interaction $\left[F(4,24)=3.01, M S_{\mathrm{e}}=\right.$ $51,867, p<.05]$. No other effects in the item analysis were significant.

Recall accuracy. To assess recall performance, each passage was propositionalized within the framework outlined by van Dijk and Kintsch (1983) and Turner and Greene (1978). Additionally, the level of detail for each proposition within the passages was identified to determine the degree to which individual propositions were critical to interpretation of the passage (van Dijk \& Kintsch, 1983; Turner \& Greene, 1978). Within this system, the level of importance of each proposition was rated $(1=$ most important; 5 = least important $)$. Propositions rated as Level 1 or 2 were defined as main idea units, propositions rated as Level 3 or 4 were defined as midlevel 


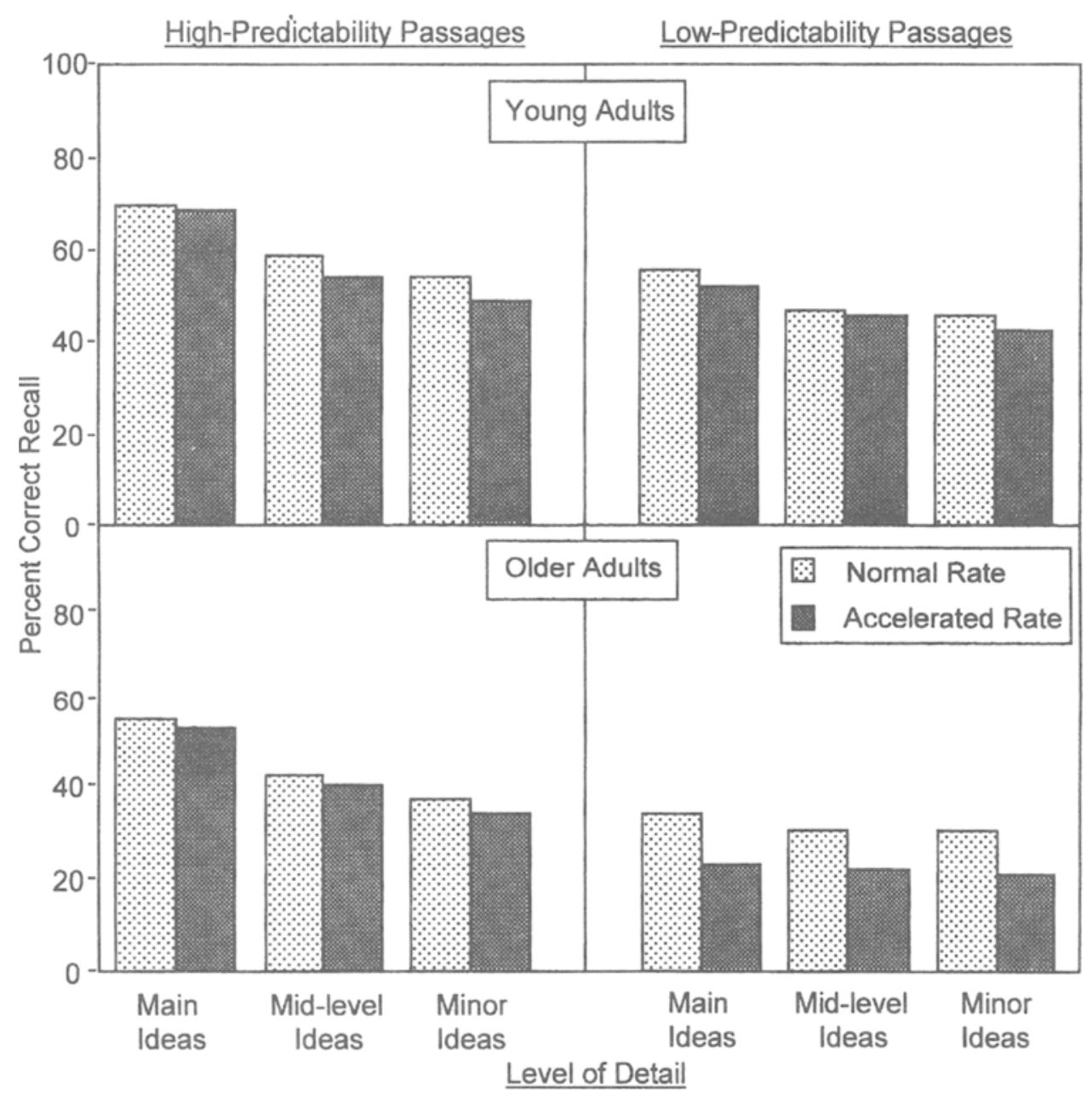

Figure 2. Percent of correctly recalled propositions in Experiment 1 as a function of age, passage predictability, level of detail, and speech rate.

idea units, and those rated 5 and higher were defined as minor idea units. Detail level was used as a grouping variable in all recall analyses.

Figure 2 shows the mean percentage of propositions correctly recalled by young and older adults at normal and accelerated speech rates for the high- (left panels) and the low- (right panels) predictability passages for the young (top panels) and older (bottom panels) adults. A 2 (age: young, older) $\times 2$ (passage predictability: high, low) $\times 2$ (speech rate: normal, accelerated) $\times 3$ (detail level: main idea units, midlevel idea units, minor idea units) mixed-design ANOVA confirmed the trends seen in Figure 2.

Figure 2 shows that recall performance for the young adults was better than recall performance for the older adults $\left[F(1,42)=39.42, M S_{\mathrm{e}}=1,172, p<.01\right]$. As can be seen by comparing the left and right panels of Figure 2, for both age groups and speech rates, recall performance was better for high-predictability passages than it was for low-predictability passages $\left[F(1,42)=138.00, M S_{\mathrm{e}}=\right.$ $178, p<.01]$. Similarly, for both age groups collapsed across passage predictability, recall performance was better for normal rate passages than it was for accelerated rate passages $\left[F(1,42)=13.29, M S_{\mathrm{e}}=196, p<.01\right]$. Significant age interactions with predictability and speech rate, however, suggest that increases in speech rate and decreases in predictability differentially disrupted recall for the older adults. This was seen in significant age $\times$ passage predictability $\left[F(1,42)=5.92, M S_{\mathrm{e}}=178, p<\right.$ $.05]$ and age $\times$ passage predictability $\times$ speech rate $\left[F(1,42)=5.34, M S_{\mathrm{e}}=107, p<.05\right]$ interactions.

As is evident in Figure 2, propositions having a higher level of importance (main idea units) were better recalled than propositions having a lower level of importance (midlevel and minor idea units) $\left[F(2,84)=99.32, M S_{\mathrm{e}}=70\right.$, $p<.01]$. This levels effect, however, was lower for lowpredictability passages, reflected in a significant detail level $\times$ passage predictability interaction $[F(2,84)=$ $\left.26.08, M S_{\mathrm{e}}=64, p<.01\right]$.

We also conducted an item analysis on the recall data. As in the participant analysis, there was a significant main effect of age $\left[F 2(1,6)=11.46, M S_{\mathrm{e}}=90, p<.05\right]$ 
and a significant age $\times$ predictability $\times$ speech rate interaction $\left[F 2(1,6)=12.59, M S_{\mathrm{e}}=81, p<.05\right]$. However, there was a significant predictability $\times$ speech rate interaction $\left[F 2(1,6)=8.30, M S_{\mathrm{e}}=81, p<.05\right]$. No other effects in the item analysis were significant.

\section{Discussion}

The results of Experiment 1 suggest that although young and older adults are similar in how they listen to discourse, they differ in several respects. Young adults, for example, gave themselves more time to process linguistically important regions of text for passages of low contextual predictability. Although older adults did take some advantage of the opportunity to listen to passages at their own pace (e.g., by spending more time at sentence boundaries and at segments containing low-frequency words), they did not change their pattern of listening time as a function of increases in speech rate and passage predictability.

The pattern of data obtained in Experiment 1 raises the possibility that the age-related difficulties in memory for spoken discourse may have been at least in part a consequence of differences in how resources were allocated during encoding. We tested this possibility more directly in Experiment 2 by comparing recall for spoken materials when it was or was not possible for participants to control the flow of speech. In Experiment 2, passages were either presented for recall in a self-paced fashion, as in Experiment 1 , or in a full-passage presentation condition without interruption. If encoding strategies utilized by young adults are helpful in promoting good comprehension and recall of spoken discourse, young adults should show a greater benefit in their memory for spoken discourse when they have control over the flow of information than when they do not. In contrast, if older adults' encoding strategies are less helpful in promoting good recall and comprehension of spoken discourse, there should be a smaller difference in their memory performance when passages are encoded at a predetermined or a participantdetermined rate.

Given these hypotheses, our focus in Experiment 2 was on the pattern of recall for young and older adults and the manner of passage presentation. Because we were concerned that the presentation of more than 8 experimental passages and additional practice passages might have exceeded the comfort levels of our participants, we reduced the number of passages per condition and statistically collapsed across passage predictability in Experiment 2.

\section{EXPERIMENT 2}

\footnotetext{
Method

Participants. The young adults were 24 university undergraduates, 15 women and 9 men, with ages ranging from 18 to 25 years ( $M=19.3$ years). The older adults were 24 volunteers from the community, 15 women and 9 men, with ages ranging from 55 to 80 years $(M=70.8$ years $)$. The young adult group had a mean of 12.7 years of education at time of testing ( $S D=1.3$ ), and the older adult group
}

had a mean of 16 years of education $[S D=2.3 ; t(46)=3.17, p<$ $.01]$. The young adult group had a mean WAIS-R vocabulary score of $64(S D=8.7)$, and the older adult group had a mean vocabulary score of $71[S D=7.7 ; t(46)=3.19, p<.01]$. The young adult group had a mean spoken word span score of $6.0(S D=1.0)$, and the older adult group had a word span score of $5.2[S D=.72 ; t(46)=3.10$, $p<.01]$. As in the previous experiment, all participants were healthy and well educated. None were neurologically compromised by stroke or had any sign of dementing illness, and all had hearing acuity appropriate to their age group as revealed by pure-tone audiometric screening.

Stimulus Materials. Stimulus materials consisted of the same 8 passages used in Experiment 1. However, for this experiment, in addition to segmented versions of the passages, unsegmented versions were also made available for each passage at each speech rate. Both sets of passages were again time compressed to $99 \%$ and $60 \%$ of their original duration to comprise the normal speech rate $(168 \mathrm{wpm})$ and the accelerated speech rate conditions $(278 \mathrm{wpm})$, respectively. In contrast to Experiment 1, we collapsed across passage predictability in the ANOVA for Experiment 2 because the addition of the full-passage presentation condition resulted in only 1 passage per condition.

Procedure. All procedures were identical to those used in Experiment 1 except for the inclusion of the full-passage presentation condition. In this condition, participants were instructed to press an appropriately labeled key that initiated presentation of the entire passage that played through to the end without interruption. As in Experiment 1, participants were instructed to recall as much of each passage as possible at its conclusion.

Each participant heard a total of 8 spoken passages. Four passages occurred in each presentation condition (full and self-paced) and in each speech rate condition (normal and accelerated), resulting in a total of 2 passages per condition. Participants were informed as to the presentation and speech rate conditions of a given passage prior to its presentation. Passages were counterbalanced across participants so that by the end of the experiment each passage had been presented an equal number of times in each condition.

\section{Results}

Pause durations for self-paced passage presentation. As in Experiment 1, listener-controlled pause durations were measured as a function of the kind of boundary created by the segmentation procedure and where in the time course of the passage the segment occurred. Figure 3 shows mean pause durations (in milliseconds) for the young and older participants with respect to segment type for the first, second, and final thirds of the passages. As in Experiment 1 , lines of best fit across passage position are plotted for each of the conditions and text variables; speech rate is again not depicted because it produced no statistically significant effect on the pattern of pause durations $[F(46)<1]$. The results of a 2 (age: young, older) $\times 2$ (presentation condition: self-paced, full) $\times 3$ (boundary type: within clause, end of clause, end of sentence) $\times 3$ (passage position: first third, second third, final third) $\times 2$ (speech rate: normal, accelerated) ANOVA confirmed the major trends suggested by Figure 3.

Three of the major trends described in Experiment 1 were replicated in Experiment 2 and are depicted in Figure 3. First, there was no main effect of age in the pause duration data, indicating that when all segment types were collapsed, the young and older adults showed sim- 


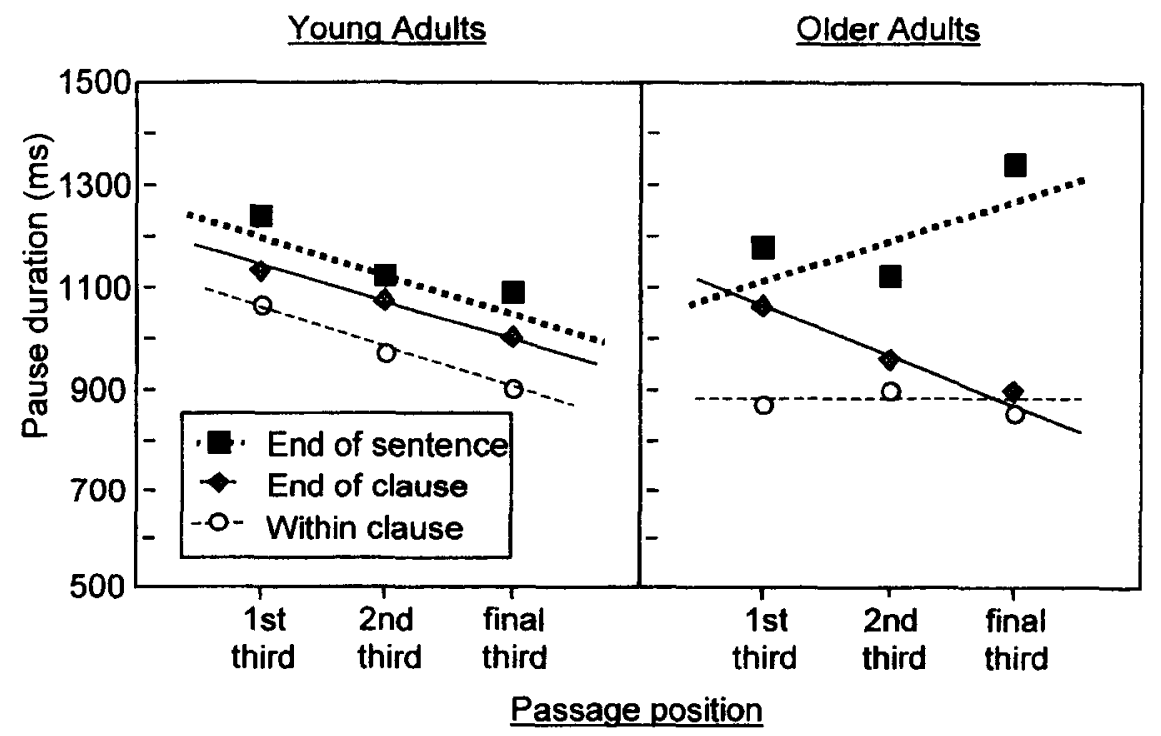

Figure 3. Mean pause duration in milliseconds in Experiment 2 as a function of age, passage position, and boundary type.

ilar pause durations $[F(1,46)<1]$. Second, there was a main effect of boundary type, consistent with a tendency for participants to pause longer at boundaries of greater linguistic importance $\left[F(2,92)=38.24, M S_{\mathrm{e}}=127,957\right.$, $p<.01]$. There was, however, a significant age $\times$ boundary type interaction showing this effect to be greater for the older adults $\left[F(2,92)=5.18, M S_{\mathrm{e}}=127,957, p<\right.$ $.01]$, a trend that was not statistically supported in Experiment 1 . This effect of boundary type increased as more of the passage was heard, as reflected in a significant boundary type $\times$ passage position interaction $[F(4,184)=$ $\left.4.00, M S_{\mathrm{e}}=60,098, p<.01\right]$. However, this latter interaction was carried primarily by the older adults' performance, as evidenced by a significant boundary type $\times$ passage position $\times$ age interaction $\left[F(4,184)=3.76, M S_{\mathrm{e}}=\right.$ $60,098, p<.01]$. These data confirm the finding of Experiment 1 that young adults' pause durations at sentence boundaries decreased across a passage, whereas the older adults' pause durations increased at sentence boundaries.

As in Experiment 1, a stepwise regression analysis showed that listeners were sensitive to characteristics such as the accumulation of segments across a sentence and across a passage, as well as propositional density, average word frequency, and segment length. ${ }^{2}$

Recall accuracy. Figure 4 depicts the recall data from Experiment 2 as a function of age, presentation condition, speech rate, and detail level. A 2 (age: young, older) $\times 2$ (presentation condition: full, self-paced) $\times 2$ (speech rate: normal, accelerated) $\times 2$ (detail level: main idea units, midlevel idea units, minor idea units) mixed-design ANOVA confirmed the major trends seen in Figure 4.

As can be seen by comparing the upper and lower panels of Figure 4, recall performance for the young adults was better than recall performance for the older adults $\left[F(1,46)=26.55, M S_{\mathrm{e}}=793, p<.01\right]$. Additionally, re- call for both groups was better for normal rate passages than for accelerated passages $\left[F(1,46)=29.95, M S_{\mathrm{e}}=\right.$ $467, p<.01]$. Recall increased as the level of importance for individual propositions increased $[F(2,92)=61.38$, $\left.M S_{\mathrm{e}}=90, p<.01\right]$, especially in the self-paced passage presentation condition. This was confirmed by a significant detail level $\times$ presentation condition interaction $\left[F(2,92)=12.13, M S_{\mathrm{e}}=69, p<.01\right]$.

Comparison of the left and right panels of Figure 4 indicates that recall performance was better for the selfpaced presentation condition than for the full-passage presentation condition for both young and older adults $\left[F(1,46)=24.36, M S_{\mathrm{e}}=332, p<.01\right]$. However, selfpacing improved recall performance for young adults differentially more than it did for older adults, especially for main ideas, a finding supported by a significant age $\times$ presentation condition $\times$ detail level interaction $\left[F(2,92)=4.95, M S_{\mathrm{e}}=69, p<.01\right]$, and especially for main ideas in accelerated passages, as reflected by a significant age $\times$ presentation condition $\times$ detail level $\times$ speech rate interaction $\left[F(2,92)=3.93, M S_{\mathrm{e}}=76, p<\right.$ $.05]$. Finally, for young adults there was a larger difference in recall between normal and accelerated passages for the full-passage presentation condition than for the selfpaced presentation condition, a finding supported by a significant age $\times$ speech rate $\times$ presentation condition interaction $\left[F(1,46)=5.96, M S_{\mathrm{e}}=307, p<.05\right]$.

\section{Discussion}

The pattern of pause durations in the self-paced listening condition of this experiment replicated in most regards the encoding results of Experiment 1. More important, however, Experiment 2 showed that differences in processing time allocation patterns were explicitly associated with recall for the passages. In particular, young 


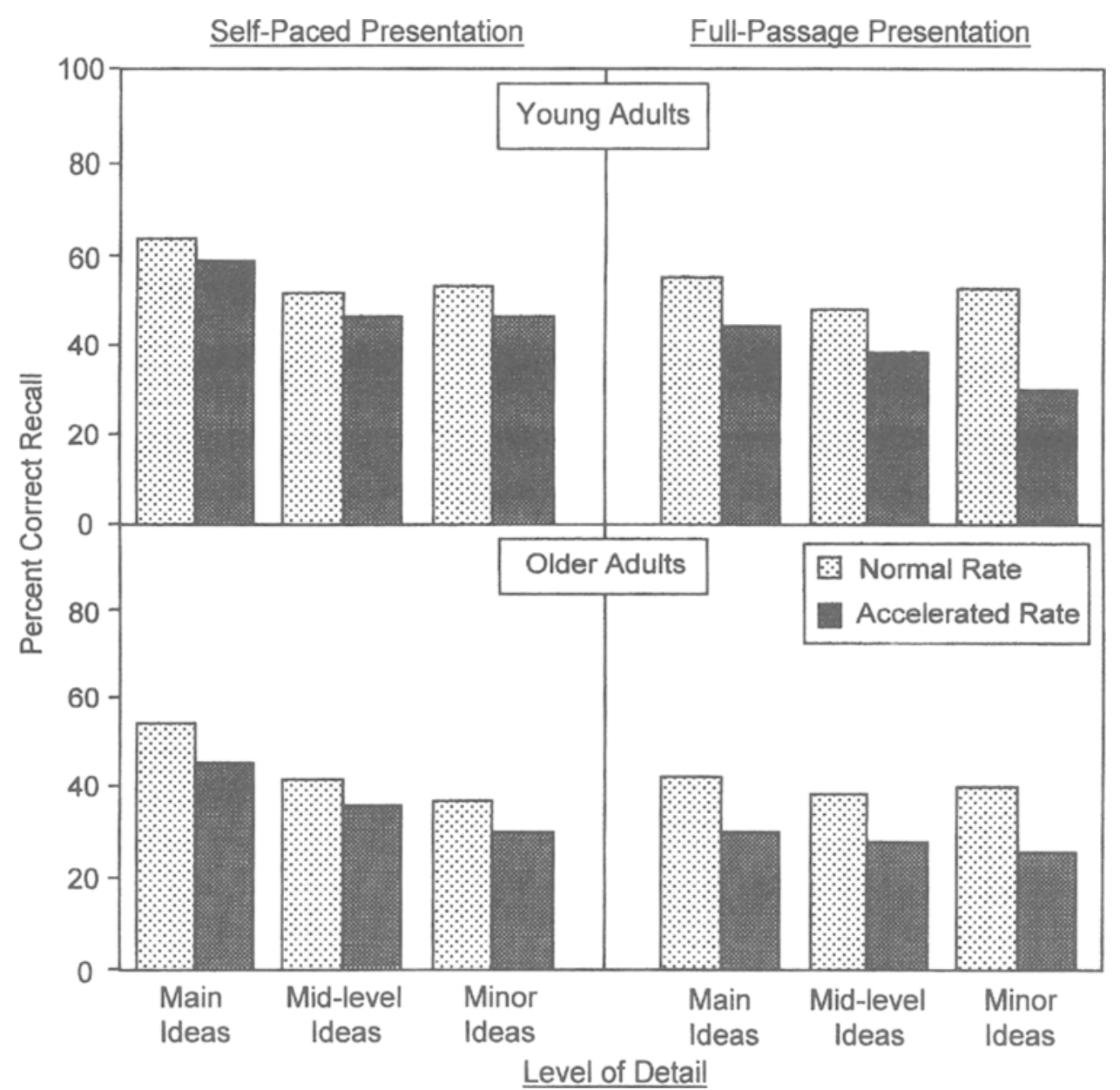

Figure 4. Percent of correctly recalled propositions in Experiment 2 as a function of age, presentation condition, level of detail, and speech rate.

adults' recall benefited differentially more than that of older adults from the opportunity to listen to the discourse passages at their own pace. This result suggests that the young adults' encoding strategy in the self-paced passage presentation condition engendered higher levels of recall than did the older adults' encoding strategy.

\section{GENERAL DISCUSSION}

In the present study, we investigated how young and older adults encode and recall spoken discourse using a self-paced listening paradigm, the AMW technique (Ferreira \& Anes, 1994; Ferreira, Anes, \& Horine, 1996; Ferreira, Henderson, et al., 1996). Taking pause durations as an indication of resource allocation at various points in a discourse passage, we found that listeners, like readers (Stine et al., 1996), do not encode all aspects of spoken discourse uniformly. Like readers, listeners tend to spend more time processing difficult portions of texts, be they at local segment levels (e.g., sentence boundaries) or at global passage levels (e.g., overall passage predictability). Furthermore, they tend to spend more time processing information at syntactically relevant boundaries (e.g., clauses and sentences), which is also consistent with findings routinely observed in reading studies (e.g., Just et al., 1982; Magliano et al., 1993). Our study of both older and younger adults adds support for the position that the AMW technique is as effective as self-paced reading paradigms in elucidating patterns of encoding during discourse processing.

We had predicted that older adults, unlike young adults, would fail to adjust their listening strategies as a function of increases in text difficulty, but that more automatic aspects of discourse processing would be similar to the patterns found for young adults. Such age-related encoding differences would also be manifest in the recall behavior of young and older adults, particularly for difficult passages (passages of low contextual predictability and/or accelerated speech rate).

Across both experiments, young and older adults' pause durations were sensitive to a number of text factors during spoken discourse processing that are similar to those found in studies of reading times. First, as in reading, both groups allocated more resources to syntactically 
important boundary regions of texts, such as sentence boundaries (e.g., Stine, 1990). This result is likely to underlie the finding for both young and older participants that processing time increases as more of a sentence is heard. Further, although the effect was small, the regression analyses show that both young and older adults allocated more processing time to propositionally dense segments, and in Experiment 2, to segments of a lower average word frequency. (Experiment 1 showed a word frequency effect only for older adults.) It is noteworthy that a small effect of word frequency was found in our experiments. Ferreira, Henderson, et al. (1996) found an effect of word frequency for young adults using single-word segments, while we used multiple-word segments. It is possible that the use of multiple-word segments diluted the effects of word frequency, although the data suggest that this did not occur.

In contrast to these similarities, there were a number of differences in how young and older adults allocated their processing resources across the spoken passages. In general, participants' pause times suggest that the young adults tended to alter their encoding behavior to accommodate increases in textual difficulty to a degree not observed in the older adults. In particular, the young adults tended to increase the time spent at clause boundaries for low-predictability passages, whereas the older adults did not. ${ }^{3}$ Additionally, young adults allocated relatively more processing time at the beginnings of passages than at the ends of passages (see Ferreira \& Henderson, 1990, for a similar pattern of results for young adult readers), whereas older adults did not. These results suggest that young adults more adaptively allocated processing resources to difficult aspects of the texts to help to overcome potential comprehension failures. That the encoding strategies of young adults were more effective than those of the older adults can be seen in Experiment 2. These results show that the young adults' recall performance improved to a greater degree than the older adults' when they were allowed to control the delivery of the input relative to when passages were presented without the opportunity for selfpacing.

It would thus seem to follow that the older adults' listening behaviors were relatively inadequate in producing good recall relative to the young adults' because they failed to adaptively change their resource allocation patterns in a way observed for the young adults (Hartley, 1993; Stine et al., 1996). Although neither the young nor the older adults' pause durations were slowed by increases in the speech rate of the passages, older adults' recall was differentially affected by speech rate. Given that a failure to accommodate for increases in speech rate did not affect young adults as much as it did older adults during recall, one might reasonably infer that older adults require additional processing time during encoding to achieve comparable levels of recall as the young. This age-invariant pattern of encoding in the face of poorer recall suggests a limitation on the part of the older comprehender in appropriately allocating resources where necessary.
Although the patterns of resource allocation for young and older adults during listening and reading are generally similar, this study highlighted some differences. For example, Stine et al. (1996) found that older adults were slower readers overall than young adults. In the present study, by contrast, we found no difference in overall pause durations between young and older adults, even though the task of listening to discourse might be considered more resource demanding than the task of reading. Further, both we and Stine et al. (1996) found that older comprehenders were less sensitive than young adult comprehenders to the text-based level of representation (e.g., propositional density in the present study and propositional content and new arguments in the reading study). Older adults have been shown to modulate their reading time as a function of propositional density for individual sentences (Stine \& Hindman, 1994), although this discrepancy might be due to differences in how isolated sentences and connected discourse are encoded.

Other studies have shown that older adult readers tend to spend relatively less time on the ends of syntactic constituents such as ends of clauses and sentences than do young readers (L. M. S. Miller \& Stine-Morrow, 1998; Stine, 1990; Stine \& Hindman, 1994). Although the older adults in the present study paused significantly longer at the ends of sentences than at the other boundary types, they spent less time than the young at the ends of clauses. It might be that the prosodic information that is present at these boundaries in spoken discourse, but absent during on-line reading, promotes a listening strategy in which older adults focus more attention on integrating text information at the ends of sentences than at other boundary positions.

Finally, reading studies have indicated that both young and older adults' reading times decrease as more of a passage is read (L. M. S. Miller \& Stine-Morrow, 1998; Stine et al., 1995; Stine et al., 1996). This pattern of data has been interpreted in the reading literature as reflecting the initial construction of a situational discourse model early in the texts that facilitates the subsequent encoding of text material (e.g., Gernsbacher, 1990). To the extent that this interpretation is correct, it would suggest that in our listening studies the older adults failed to devote sufficient time to the beginnings of passages, with the result that later information could not be easily integrated into a partially developed discourse structure. Indeed, our results indicate that older adults spent more time at the ends of discourse passages, suggesting that it became increasingly more difficult for them to integrate new information with previously heard material.

The results from both the present study and from previous reading studies suggest that older adults have more difficulty than young adults in flexibly allocating resources as a function of text difficulty. What remains unclear, however, are the mechanisms for this age-related limitation. Although there is a general recognition that perceptual and cognitive slowing is common in normal aging (Salthouse, 1991, 1994), the young and older adults 
in the present study did not differ in their average listening speed.

The age differences would thus seem to lie in differences in self-initiated encoding strategies that might exist because older adults fail to monitor their level of comprehension or memory when listening to discourse (Bieman-Copland \& Charness, 1994; Connor, Dunlosky, \& Hertzog, 1997) or because they fail to take appropriate corrective action when their capacity limits are being reached (Dunlosky \& Connor, 1997; Zabrucky \& Moore, 1994). We do not believe that this difficulty resides in the older adults' knowledge of language structure or the procedural rules governing the application of this knowledge, factors that are known to remain stable in normal aging (Light, 1990). Rather, the difficulty seems to reside in an age-related deficit in the control of processing resources and the ability to allocate these resources appropriately in the face of declining memory ability.

\section{REFERENCES}

Aaronson, D., \& Ferres, S. (1984). The word-by-word reading paradigm: An experimental and theoretical approach. In D. E. Kieras \& M. A. Just (Eds.), New methods in reading comprehension research (pp. 31-68). Hillsdale, NJ: Erlbaum.

aaronson, D., \& Scarborough, H. S. (1976). Performance theories for sentence coding: Some qualitative evidence. Journal of Experimental Psychology: Human Perception \& Performance, 2, 56-70.

ACQuino, M. R. (1969). The validity of the Miller-Coleman readability scale. Reading Research Quarterly, 4, 332-357.

Bieman-Copland, S., \& Charness, N. (1994). Memory knowledge and memory monitoring in adulthood. Psychology \& Aging, 9, 287-302.

CAPLAN, D., \& WATERS, G. S. (1999). Verbal working memory and sentence comprehension. Behavioral \& Brain Sciences, 22, 77-126.

Carpenter, P. A., MiYaki, A., \& Just, M. A. (1994). Working memory constraints in comprehension: Evidence from individual differences, aphasia, and aging. In M. A. Gernsbacher (Ed.), Handbook of psycholinguistics (pp. 1075-1122). San Diego: Academic Press.

Cohen, J. D., MacWhinney, B., Flatt, M., \& Provost, J. (1993). PsyScope: An interactive system for designing and controlling experiments in the psychology laboratory using Macintosh computers. $B e$ havior Research Methods, Instruments, \& Computers, 25, 257-271.

ConNor, L. T., Dunlosky, J., \& HerTZOG, C. (1997). Age-related differences in absolute but not relative metamemory accuracy. Psychology \& Aging, 12, 50-71.

CraIK, F. I. M., \& BYRD, M. (1982). Aging and cognitive deficits: The role of attentional processes. In F. I. M. Craik \& S. Trehub (Eds.), Aging and cognitive processes (pp. 191-211). New York: Plenum.

Craik, F. I. M., \& Jennings, J. M. (1992). Human memory. In F. I. M. Craik \& T. A. Salthouse (Eds.), The handbook of aging and cognition (pp. 51-110). Hillsdale, NJ: Erlbaum.

Daneman, M., \& CaRPEnTER, P. A. (1980). Individual differences in working memory and reading. Journal of Verbal Learning \& Verbal Behavior, 23, 569-578.

Daneman, M., \& Merikle, P. M. (1996). Working memory and language comprehension: A meta-analysis. Psychonomic Bulletin \& Review, $\mathbf{3}$, 422-433.

DUNLOSKY, J., \& ConNOR, L. T. (1997). Age differences in the allocation of study time account for age differences in memory performance. Memory \& Cognition, 25, 691-700.

Ferreira, F., \& ANES, M. D. (1994). Why study spoken language processing? In M. A. Gernsbacher (Ed.), Handbook of psycholinguistics (pp. 33-56). San Diego: Academic Press.

Ferreira, F., ANes, D., \& Horine, M. D. (1996). Exploring the use of prosody during language comprehension using the auditory moving window technique. Journal of Psycholinguistic Research, 25, 273-290.

Ferreira, F., \& Henderson, J. M. (1990). The use of verb information in syntactic parsing: A comparison of evidence from eye movements and word-by-word self-paced reading. Journal of Experimental Psychology: Learning, Memory, \& Cognition, 16, 555-568.

Ferreira, F., Henderson, J. M., Anes, M. D., Weeks, P. A., \& MCFarLANE, D. K. (1996). Effects of lexical frequency and syntactic complexity in spoken language comprehension: Evidence from the Auditory Moving Window technique. Journal of Experimental Psychology: Learning, Memory, \& Cognition, 22, 324-335.

FrANCIS, W. N., \& KuČERA, H. (1982). Frequency analysis of English usage. Boston: Houghton Mifflin.

GERNSBACHER, M. A. (1990). Language comprehension as structure building. Hillsdale, $\mathrm{NJ}$ : Erlbaum.

HARTLEY, J. T. (1986). Reader and text variables as determinants of discourse memory in adulthood. Psychology \& Aging, 1, 150-158.

HARTLEY, J. T. (1993). Aging and prose memory: Tests of the resourcedeficit hypothesis. Psychology \& Aging, 8, 538-551.

Hartley, J. T., Stojack, C. C., Mushaney, T. J., Annon, T. A. K., \& LEE, D. W. (1994). Reading speed and prose memory in older and younger adults. Psychology \& Aging, 9, 216-223.

Just, M. A., Carpenter, P. A., \& WoOlley, J. D. (1982). Paradigms and processes in reading comprehension. Journal of Experimental Psychology: General, 111, 228-238.

Kahneman, D. (1973). Attention and effort. Englewood Cliffs, NJ: Prentice-Hall.

KINTSCH, W. (1994). The psychology of discourse processing. In M. A. Gernsbacher (Ed.), Handbook of psycholinguistics (pp. 721-739). San Diego: Academic Press.

LIGHT, L. L. (1990). Interactions between memory and language in old age. In J. E. Birren \& K. W. Schaie (Eds.), Handbook of the psychology of aging (3rd ed., pp. 275-290). San Diego: Academic Press.

Magliano, J. P., Graesser, A. C., Eymard, L. A., Haberlandt, K., \& GHolson, B. (1993). Locus of interpretive and inference processes during text comprehension: A comparison of gaze durations and word reading times. Journal of Experimental Psychology: Learning, Memory, \& Cognition, 19, 704-709.

Miller, G. R., \& Coleman, E. B. (1967). A set of thirty-six prose passages calibrated for complexity. Journal of Verbal Learning \& Verbal Behavior, 6, 851-854.

Miller, L. M. S., \& Stine-Morrow, E. A. L. (1998). Aging and the effects of knowledge on on-line reading strategies. Journal of Gerontology: Psychological Sciences, 53, 223-233.

Riggs, K. M., Wingfield, A., \& Tun, P. A. (1993). Passage difficulty, speech rate, and age differences in memory for spoken text: Speech recall and the complexity hypothesis. Experimental Aging Research, 19, 111-128.

SALTHOUSE, T. A. (1991). Theoretical perspectives on cognitive aging. Hillsdale, NJ: Erlbaum.

SALTHOUSE, T. A. (1994). The nature of the influence of speed on adult age differences in cognition. Developmental Psychology, 30, 240-259.

Salthouse, T. A., \& BabCock, R. L. (1991). Decomposing adult age differences in working memory. Developmental Psychology, 27, 763-776.

Stine, E. A. L. (1990). On-line processing of written text by younger and older adults. Psychology \& Aging, 5, 68-78.

StiNE, E. A. L. (1995). Aging and the distribution of resources in working memory. In P. Allen \& T. R. Bashore (Eds.), Age differences in word and language processing (pp. 171-186). Amsterdam: Elsevier, North-Holland.

Stine, E. A. L., Cheung, H., \& Henderson, D. T. (1995). Adult age differences in the on-line processing of new concepts in discourse. Aging \& Cognition, 2, 1-18.

Stine, E. A. L., \& Hindman, J. (1994). Age differences in reading time allocation for propositionally dense sentences. Aging \& Cognition, 1 , 2-16.

Stine, E. A. L., Loveless, M. K., \& Soederberg, L. M. (1996). Re- 
source allocation in on-line reading by younger and older adults. Psychology \& Aging, 11, 475-486.

STINE, E. A. L., \& WingField, A. (1990). How much do working memory deficits contribute to age differences in discourse processing? European Journal of Cognitive Psychology, 2, 289-304.

Turner, A., \& Greene, F. (1978). Construction and use of a propositional text base. JSAS: Catalog of Selected Documents in Psychology, 8, 3. (MS. No. 1713)

vaN DiJK, T. A., \& KINTSCH, W. (1983). Strategies of discourse comprehension. New York: Academic Press.

WATERS, G. S., \& CAPLAN, D. (1996). The capacity theory of sentence comprehension: Critique of Just and Carpenter (1992). Psychological Review, 103, 761-772.

WeCHSLER, D. (1981). Wechsler Adult Intelligence Scale-Revised. New York: Psychological Corp.

WingFIELD, A., \& BUTTERWORTH, B. (1984). Running memory for sentences and parts of sentences: Syntactic parsing as a control function in working memory. In H. Bouma \& D. G. Bouwhuis (Eds.), Attention and performance $X$ : Control of language processes (pp. 351363). New York: Academic Press

WingField, A., \& LiNDFiELD, K. C. (1995). Multiple memory systems in the processing of speech: Evidence from aging. Experimental Aging Research, 21, 101-121.

WingField, A., \& STINE, E. A. L. (1992). Age differences in perceptual processing and memory for spoken language. In J. D. Sinnott \& R. L. West (Eds.), Everyday memory and aging: Current research and methodology (pp. 101-123). New York: Springer-Verlag.

Wingfield, A., Stine, E. A. L., Lahar, C. J., \& Aberdeen, J. S. (1988). Does the capacity of working memory change with age? $E x$ perimental Aging Research, 14, 103-107.

ZABRUCKY, K., \& MOORE, D. (1994). Contributions of working memory and evaluation and regulation of understanding to adults' recall of texts. Journal of Gerontology, 49, 201-212.

\section{NOTES}

1. To further examine how pause durations were influenced by text characteristics, we conducted a stepwise regression analysis on these data. Pause durations for young and older adults were positively related to the propositional density of segments (i.e., as propositional density increased, so did participants' pause durations), and the number of preceding segments within a sentence (i.e., pause durations grew longer as more of a sentence accumulated). Pause durations showed a negative relationship with the number of segments accumulating across a passage (i.e., pause durations decreased as more of a passage was heard) This last effect significantly interacted with age: The decrease in pause durations across a passage was not present in the older adults' performance. Age also interacted with the average lengths of the segments in syllables (younger adults' pause durations were unaffected by segment length, whereas older adults' pause durations decreased for longer segments). Age also interacted with word frequency (Francis \& Kučera 1982), with the older adults more likely than the young adults to pause tonger for segments with lower mean word frequencies.

2. A stepwise regression analysis conducted on the pause duration data for Experiment 2 showed results similar to those reported for Experiment 1 for propositional density, the number of preceding segments within a sentence, the number of preceding segments within a passage, and the interaction between age and the effect on pause durations of the number of segments within a passage. Experiment 2 differed from Ex- periment 1 in that age did not interact with word frequency (Francis \& Kučera, 1982); both young and older adults' pause durations were slower for segments containing low-frequency words. Nor was there an age interaction for the effect of segment length as measured by number of syllables; both young and older adults' pause durations grew longer as the number of syllables in a passage increased

3. It is possible that pause durations at clause boundaries might have been shorter if we had not required participants to recall information from the passages but rather had assessed comprehension through recognitionbased question-answer tests (see Aaronson \& Scarborough, 1976, for discussion of this point in the domain of reading).

\section{APPENDIX Sample Passages Used in Experiment 1}

\section{Example High-Predictability Passage}

A nobleman and a merchant / met in a tavern. /// For their lunch / they ordered soup. /// When it was brought, // the nobleman took a spoonful, // but the soup was so hot / that he burned his mouth // and tears came to his eyes. /// The merchant asked/ why he was weeping. /// The nobleman was ashamed/ to admit he had burned his mouth and answered, // "Sir, I once had a brother who committed a great crime, / for which he was hanged. /// I was thinking of his death, // and that made me weep." /// The merchant believed this story // and began to eat his soup. /// He too burned his mouth, // so that he had tears in his eyes. /// The nobleman noticed it // and asked the merchant "Sir, // why do you weep?" /// The merchant, // who now saw the nobleman had deceived him, // answered "My lord, // I am weeping because you were not hanged/together with your brother." //I

\section{Example Low-Predictability Passage}

Their airplane had been / forced down at sea. /// They barely had time to inflate / the yellow rubber dinghies // and climb into them before the plane sank. /// Would a rescue plane find them? /// One did finally. /// To the surprise of the anxious watchers, // they saw a boat hanging under it. // The boat was aimed // and dropped from the plane. /// Parachutes opened // and let it down gently / about a hundred yards from the dinghies. /// A sea anchor shot from the front. /// A long, light line/ shot from each side. // When the men pulled themselves into the boat by these lines, // they found it equipped with two outboard motors, // sails, compass, charts, // waterproofed instructions for everything in four languages, // dry clothes, food, cigarettes, knives, fishing tackle; // everything but a welcome mat. /// All this was provided / to make sure that they would keep afloat and alive // until they could make harbor or be rescued. ///

Note-Within-clause, end-of-clause, and end-of-sentence boundaries indicated by " $/, "$ " //," and " $/ / /$, ," respectively.

(Manuscript received November 16,1998; revision accepted for publication October 10, 1999.) 